\title{
Echo-Doppler left ventricular filling abnormalities in patients with rheumatoid arthritis without clinically evident cardiovascular disease
}

\author{
S. CORRAO, L. SALLÌ, S. ARNONE, R. SCAGLIONE, A. PINTO \& G. LICATA Institute of Internal Medicine, \\ University of Palermo, Palermo, Italy
}

Received 25 April 1995 and in revised form 17 August 1995; accepted 25 August 1995

\begin{abstract}
Our investigation aimed at verifying diastolic abnormalities in rheumatoid patients, without clinically evident cardiovascular disease and other confounding complaints, by using pulsed Doppler examination of transmitral blood flow. We selected 40 patients fulfilling revised American Rheumatism Association (ARA) criteria for the diagnosis of rheumatoid arthritis having no symptoms of cardiac disease or clinical findings of other extracardiac diseases. We also studied 40 rheumatoidmatched healthy volunteers as a control group. An echocardiographic examination was carried out on each subject. Left ventricular structural and functional measurements were obtained. Interventricular septal thickness and left ventricular mass index were significantly higher in rheumatoid patients than in the control group. We also found in rheumatoid patients higher mean values of peak A velocity and $\mathrm{A} / \mathrm{E}$ ratio. When multiple linear regression analysis was performed on the data of rheumatoid patients we found an independent relationship only between $\mathrm{A} / \mathrm{E}$ ratio and left ventricular mass. In conclusion, our results confirm diastolic abnormalities in rheumatoid patients and point out that these abnormalities also affect echo-Doppler parameters of left ventricular filling. Moreover, further analysis of our data may suggest the possibility that structural left ventricle changes could be responsible for left ventricular filling impairment.
\end{abstract}

Keywords: Doppler echocardiography, left ventricular filling, pathophysiology, rheumatoid arthritis.

\section{Introduction}

Rheumatoid arthritis (RA) is associated with an increased mortality from various causes [1-3]. The most common causes of death are amyloidosis, renal diseases and infections [1-4]. There is also evidence of an excess mortality from cardiovascular disease in some [1,3] but not in all studies [2]. A study of a large group of subjects [5] has also shown a high proportion of deaths from cardiovascular causes. In addition, our

Correspondence: S. Corrao, Institute of Internal Medicine, Piazza Delle Cliniche, 2, 90127 Palermo, Italy. echocardiographic observations underline the importance of cardiac involvement in RA patients with no symptoms of cardiac disease [6].

The excess of cardiovascular mortality in these patients has been found to be related to congestive heart failure in particular and not to coronary heart disease or hypertension $[5,7,8]$. Therefore, it is likely that the rheumatoid patient could have an unrecognized involvement of the heart with consequent progressive changes in left ventricle structure. These might manifest themselves in abnormalities of left ventricular diastolic function, possibly earlier than in left ventricular systolic function.

Some echocardiographic studies have demonstrated disturbances in left ventricular diastolic function of RA patients $[9,10]$. But the reason for these abnormalities is not yet fully understood. Moreover, to our knowledge, no data are available upon echo-Doppler left ventricular filling.

Firstly, our investigation aimed at verifying diastolic abnormalities in RA patients, without confounding factors, by using pulsed Doppler examination of transmitral blood flow. Secondly, if this was shown to be the case we would have looked for links between clinical and echocardiographic data in order to try to provide a pathophysiological explanation.

\section{Patients and methods}

\section{Subject selection and study procedure}

We selected 40 subjects (eight men, 32 women), from a patient population aged $50 \pm 11$ years referred to our rheumatological outpatient clinic. All patients were in sinus rhythm. All the subjects were informed of the purpose of the study and gave their consent. The study was also approved by the Ethics Committee of our Institution. All patients fulfilled the revised American Rheumatism Association (ARA) criteria for the diagnosis of RA [11] and had no symptoms of cardiac disease. None had signs and/or symptoms of disease activity at the time of study. Patient evaluation included a complete history, physical examination, a 12-lead electrocardiogram and a standard echocardiogram. All 
patients had routine laboratory studies, including complete blood count, erythrocyte sedimentation rate by the Westergren method and the latex test to determine whether there was a positive rheumatoid factor. Blood pressure was measured using a mercury sphigmomanometer on three visits at 1 -week intervals. At each visit the same clinician took three readings of blood pressure and heart rate. The average of the last set of readings was used as clinical measurements. Diastolic blood pressure refers to Korotkoff $\mathrm{V}$ phase.

We excluded from the study all patients having a history and/or clinical findings of rheumatic fever, arterial hypertension, arterial hypotension, diabetes mellitus, primary cardiomiopathy, congenital heart diseases, other connective tissue diseases (congenital and inflammatory) and myocardial, endocardial and valvular diseases. As a control group we studied 40 volunteers, aged $50 \pm 12$ years, randomly selected among a larger group of healthy subjects without symptoms, signs and/or clinical findings of cardiac or extracardiac diseases. All of them were in sinus rhythm. Randomization was performed by links in order to obtain a rheumatoid-matched control group for some relevant variables (gender, age, body mass index, lifestyle and family history of hypertension).

All subjects underwent echocardiographic examination. However, RA patients discontinued any therapy for a period of at least 10 days before echocardiographic examination. Moreover, no patient had received steroids in the last 4 months. The two study groups, homogeneous for the above-mentioned variables, were compared. More analyses were performed on RA patients.

\section{Echocardiographic examination}

Between 08.00 and $11.00 \mathrm{~h}$, a standard two-dimensional, M-mode and Doppler echocardiographic examination was carried out on each subject in a partial left lateral recumbent position. An Esaote Biomedica computeraided ultrasonoscope equipped with $2 \cdot 5-$ and $3 \cdot 5-\mathrm{MHz}$ phased-array transducers was used; a standard VHS video format was used for recordings. Both transducers are capable of continuous Doppler activity, have pulsed Doppler capacity with a moveable Doppler cursor and an adjustable sample volume size. The sample volume size was set at $4 \mathrm{~mm}$ for this study.

A two-dimensional echocardiographic study was performed, including parasternal long-axis and short-axis views and apical four- and two-chamber views.

Left ventricular internal dimension and septal and posterior wall thickness were measured at enddiastole and end-systole, according to the American Society of Echocardiography guidelines [12], and used for all purposes except determination of left ventricular mass. In this last case, measurements were made according to the Penn convention described by Devereux and Reichek [13,14]:

$$
\begin{aligned}
\operatorname{LV} \text { mass }(\mathrm{g})= & 1 \cdot 04\left[(\mathrm{LVID}+\mathrm{VST}+\mathrm{PWT})^{3}\right. \\
& \left.-(\mathrm{LVID})^{3}\right]-13 \cdot 6
\end{aligned}
$$

where $\mathrm{LVID}=$ diastolic $\mathrm{LV}$ internal diameter, $\mathrm{VST}=$ diastolic ventricular septal thickness and PWT = diastolic posterior wall thickness. Measurements points were taken at the peak of the $\mathrm{R}$ wave on the simultaneous electrocardiogram on an average of four cycles.

Left ventricular end-diastolic and end-systolic volumes were calculated from the apical four-chamber view, using the ellipsoid single-plane algorithm [15]. End-diastolic and end-systolic frames from five consecutive beats were selected and the endocardial outlines were traced. Both mean left ventricular volumes and ejection fraction were automatically calculated by the echocardiograph processing unit. In our laboratory left ventricular volumes and ejection fraction calculated on five consecutive beats permitted optimal reproducibility and accuracy [16].

We also carried out a standard pulsed and continuous Doppler echocardiographic examination to assess the spectral flow pattern of heart valves [17].

Pulsed Doppler examination of transmitral blood flow was performed as previously described [18], from the apical four chamber view on subjects in partial left lateral recumbent position.

We measured the following variables: the $\mathrm{RR}^{\prime}$ interval, peak $\mathrm{E}$ and $\mathrm{A}$ velocities, and the deceleration halftime of early diastolic rapid inflow [19]. The Doppler measurements reported are the average of three cardiac cycles detected at end expiration.

All the echocardiograms were performed by the same physician and each study was read independently by two observers without knowledge of clinical data.

\section{Computed measurements}

- Body mass index: weight in $\mathrm{kg} /(\text { height in } \mathrm{m})^{2}$.

- Left ventricular mass index: left ventricular mass/ body surface area.

- Left ventricular mass/height: left ventricular mass in $\mathrm{g}$ divided by height in $\mathrm{m}$.

- Ejection fraction: [(left ventricular diastolic volume - left ventricular systolic volume)/left ventricular diastolic volume] $\times 100$.

- A/E ratio: (peak A/peak B) $\times 100$.

- Deceleration half-time/RR': deceleration half-time divided by $\mathrm{RR}^{\prime}$ interval (in $\left.\mathrm{ms}\right) \times 1000$.

\section{Data analysis}

Values are reported as mean $\pm \mathrm{SD}$. A two-tailed unpaired $t$-test was used for comparison of means between the two groups. Pearson correlation coefficients were estimated to quantify the strength of association between variables. A two-tailed test of significance, based on Student's distribution, was used to test the hypothesis on correlation coefficients. Moreover, multiple linear regression analysis was used to study more complex relationships among variables. Multiple regression equations were computed. Statistics for both the equation and the variables in the equation, and analysis of variance were performed. General factorial analysis of variance was 
also performed to assess the influence of therapy on echocardiographic and echo-Doppler measurements. $P<0.05$ was considered statistically significant.

\section{Results}

The duration of disease in RA patients was $82 \pm 67$ months. Nine patients were treated with non-steroidal anti-inflammatory drugs (NSAIDs), 13 patients with NSAIDs and hydroxychloroquine and 18 patients with NSAIDs and oral gold. This classification was used as factor variable in general factorial analysis of variance.

There were no statistically significant differences between the two study groups concerning some relevant clinical data (Table 1).

Structural echocardiographic data are reported in Table 2. Left ventricular cavity size and wall thickness were normal in nearly all subjects. Only three RA patients had an interventricular septal thickness higher than the top value of normality (in our laboratory, $\leqslant 11 \mathrm{~mm}$ ) but the recomputed average, without the three over-range values, showed again a significantly higher result than that of one of the control subjects $(9 \cdot 0 \pm 1.5 \mathrm{~mm}$ vs. $8 \cdot 2 \pm 1.4 \mathrm{~mm} ; P=0.02)$. Moreover, the mean left ventricular mass (LVM) was higher in RA patients than in the control subjects, even when it was normalized to body surface area (BSA) and height, but only the difference between LVM index means was statistically significant (Table 2).

As regards echo-Doppler parameters of left ventricular diastolic filling, RA patients had both the mean peak A velocity and the mean $\mathrm{A} / \mathrm{E}$ ratio significantly higher than the control group (Table 3). We performed further analyses on the data of RA patients to find out possible relationships between and among variables. Pearson coefficient analysis showed a statistically significant association only between $\mathrm{A} / \mathrm{E}$ ratio and both age and structural left ventricular measurements (Table 4). The mean peak E velocity was also significantly correlated with left ventricular mass, but the strength of association was very low $(r=0 \cdot 19 ; P=0.03)$. When the multiple linear regression analysis was performed, we found that

Table 1. Clinical data of the rheumatoid patients: comparison with the healthy subjects

\begin{tabular}{|c|c|c|c|}
\hline & RA group & Control group & $P<$ \\
\hline Women & 32 & 32 & \\
\hline Men & 8 & 8 & \\
\hline Age (years) & $50 \pm 11$ & $50 \pm 12$ & NS \\
\hline $\begin{array}{l}\text { Body mass index } \\
\left(\mathrm{kg} \mathrm{m}^{2}\right)\end{array}$ & $25 \cdot 2 \pm 4 \cdot 3$ & $25 \cdot 6 \pm 4 \cdot 3$ & NS \\
\hline $\begin{array}{l}\text { Duration of disease } \\
\text { (years) }\end{array}$ & $6 \cdot 9 \pm 5 \cdot 4$ & - & - \\
\hline $\begin{array}{l}\text { Systolic blood pressure } \\
(\mathrm{mmHg})\end{array}$ & $124 \pm 12$ & $123 \pm 11$ & NS \\
\hline $\begin{array}{l}\text { Diastolic blood pressure } \\
(\mathrm{mmHg})\end{array}$ & $77 \pm 10$ & $76 \pm 8$ & NS \\
\hline $\begin{array}{l}\text { Heart rate } \\
\quad\left(\text { beats } \min ^{-1}\right)\end{array}$ & $78 \pm 8$ & $76 \pm 10$ & NS \\
\hline
\end{tabular}

the $\mathrm{A} / \mathrm{E}$ ratio was independently correlated only with the LVM (even when it was normalized to height) and not with age or other parameters; the results are summarized in Table 5. Such an analysis on control group data showed that $\mathrm{A} / \mathrm{E}$ ratio was correlated with age $(r=0 \cdot 45 ; P<0.006)$ and not with LVM or LVMI.

Finally, in RA patients, no relationship was

Table 2. Structural and functional data derived from M-mode and twodimensional echocardiography

\begin{tabular}{|c|c|c|c|}
\hline & RA group & Control group & $P<$ \\
\hline $\begin{array}{l}\text { IV septal thickness } \\
\text { (mm) }\end{array}$ & $9 \cdot 2 \pm 1 \cdot 9$ & $8 \cdot 2 \pm 1 \cdot 4$ & $0 \cdot 01$ \\
\hline $\begin{array}{l}\text { Posterior wall thickness } \\
\quad(\mathrm{mm})\end{array}$ & $8 \cdot 3 \pm 1 \cdot 9$ & $7 \cdot 8 \pm 1 \cdot 9$ & NS \\
\hline $\begin{array}{l}\text { LV internal diameter } \\
\text { in diastole }(\mathrm{mm})\end{array}$ & $48 \pm 5$ & $50 \pm 5$ & NS \\
\hline $\begin{array}{l}\text { LV internal diameter } \\
\text { in systole }(\mathrm{mm})\end{array}$ & $31 \pm 5$ & $32 \pm 6$ & NS \\
\hline $\begin{array}{l}\mathrm{LV} \text { mass } \\
(\mathrm{g})\end{array}$ & $132 \pm 32$ & $126 \pm 40$ & NS \\
\hline $\begin{array}{l}\text { LV mass index } \\
\left(\mathrm{g} \mathrm{m}^{-2}\right)\end{array}$ & $85 \pm 20$ & $73 \pm 21$ & 0.02 \\
\hline $\begin{array}{l}\text { LV mass/height } \\
\qquad\left(\mathrm{g} \mathrm{m}^{-1}\right)\end{array}$ & $86 \pm 21$ & $78 \pm 23$ & NS \\
\hline $\begin{array}{l}\text { LV end-diastolic volume } \\
\quad(\mathrm{mL})\end{array}$ & $111 \pm 25$ & $121 \pm 27$ & NS \\
\hline $\begin{array}{l}\text { LV end-systolic volume } \\
\text { (mL) }\end{array}$ & $44 \pm 17$ & $48 \pm 17$ & NS \\
\hline $\begin{array}{l}\text { LV ejection fraction } \\
\qquad(\%)\end{array}$ & $61 \pm 10$ & $61 \pm 6$ & NS \\
\hline
\end{tabular}

IV, interventricular; LV, left ventricular.

Table 3. Doppler transmitral flow parameters

\begin{tabular}{lccc}
\hline & RA group & Control group & $P<$ \\
\hline $\begin{array}{l}\text { Peak A velocities } \\
\left(\mathrm{m} \mathrm{s}^{-1}\right)\end{array}$ & $0 \cdot 70 \pm 0 \cdot 14$ & $0 \cdot 61 \pm 0 \cdot 14$ & $0 \cdot 006$ \\
$\begin{array}{l}\text { Peak E velocities } \\
\left(\mathrm{m} \mathrm{s}^{-1}\right)\end{array}$ & $0 \cdot 60 \pm 0 \cdot 13$ & $0 \cdot 72 \pm 0 \cdot 56$ & $\mathrm{NS}$ \\
$\begin{array}{l}\text { A/E ratio } \\
(\%)\end{array}$ & $123 \pm 36$ & $94 \pm 26$ & $0 \cdot 001$ \\
$\begin{array}{l}\text { Deceleration half-time/RR } \\
(\times 1000)\end{array}$ & $138 \pm 47$ & $132 \pm 47$ & $\mathrm{NS}$ \\
\hline
\end{tabular}

Table 4. Pearson correlation analysis performed on RA patient data: strength and significance of association between $\mathrm{A} / \mathrm{E}$ ratio and the other variables

\begin{tabular}{lll} 
Variables compared with & & $P$ \\
A/E ratio & $r$ & $0 \cdot 018$ \\
\hline Age & $0 \cdot 40$ & $0 \cdot 019$ \\
Posterior wall thickness & $0 \cdot 44$ & $0 \cdot 011$ \\
IV septal thickness & $0 \cdot 47$ & $0 \cdot 015$ \\
LV mass & $0 \cdot 47$ & $0 \cdot 009$ \\
LV mass index & $0 \cdot 50$ & $0 \cdot 007$ \\
LV mass/height & $0 \cdot 51$ & \\
\end{tabular}

IV, interventricular; LV, left ventricular. 
Table 5. The multiple linear regression analysis performed on RA patient data

\begin{tabular}{|c|c|c|c|c|c|c|}
\hline $\begin{array}{l}\text { Dependent } \\
\text { variable }\end{array}$ & $\begin{array}{l}\text { Independent } \\
\text { variables }\end{array}$ & $\begin{array}{l}\text { Partial } \\
\text { regression } \\
\text { coefficients }(B)\end{array}$ & $\begin{array}{l}\text { Standard } \\
\text { error of ' } B \text { ' }\end{array}$ & $\begin{array}{l}\text { Significance for } \\
\text { each independent } \\
\text { variable }(P<)\end{array}$ & $\begin{array}{l}R \text {-Square } \\
\text { coefficient }\left(R^{2}\right)\end{array}$ & $\begin{array}{l}\text { Analysis of } \\
\text { variance on the } \\
\text { regression }(P<)\end{array}$ \\
\hline \multicolumn{7}{|l|}{$\mathrm{A} / \mathrm{E}$ ratio } \\
\hline & Age & 0.97 & $0 \cdot 60$ & NS & \multirow[t]{2}{*}{$0 \cdot 30$} & \multirow[t]{2}{*}{0.02} \\
\hline & LVM & $0 \cdot 42$ & $0 \cdot 23$ & $0 \cdot 04$ & & \\
\hline & Age & $0 \cdot 84$ & 0.62 & NS & \multirow[t]{2}{*}{0.32} & \multirow[t]{2}{*}{0.02} \\
\hline & LVM/H & 0.73 & 0.36 & 0.05 & & \\
\hline & Age & 0.90 & 0.60 & NS & \multirow[t]{2}{*}{$0 \cdot 32$} & \multirow[t]{2}{*}{$0 \cdot 02$} \\
\hline & LVMI & $0 \cdot 75$ & 0.35 & 0.05 & & \\
\hline & Age & 0.95 & 4.53 & NS & \multirow[t]{3}{*}{$0 \cdot 32$} & \multirow[t]{3}{*}{$0 \cdot 03$} \\
\hline & IVS-t & 5.97 & $4 \cdot 67$ & NS & & \\
\hline & PW-t & 3.09 & 0.67 & NS & & \\
\hline
\end{tabular}

LVM, left ventricular mass; LVM/H, left ventricular mass/height; LVMI, left ventricular mass index; IVS-t, inter-ventricular-septal thickness; PW-t, posterior wall thickness.

found between drug therapy and echo-Doppler or echocardiographic measurements.

\section{Discussion}

The main feature of our study is the initial selection of only patients with no clinical evidence of heart disease or extracardiac complaints. The second one is the comparison with a control group matched for some relevant variables.

In our patients with RA, without clinically evident cardiovascular disease, LV systolic function evaluated by echocardiography was normal even when compared with that of the controls. This finding is in accordance with some other studies $[9,20,21]$ based on echocardiography.

On the other hand, left ventricular diastolic filling abnormalities were observed in spite of the normal left ventricular systolic function. These abnormalities concern peak $\mathrm{A}$ velocities and $\mathrm{A} / \mathrm{E}$ ratio, which were found to be higher than in the controls. In previous studies, in which left ventricular diastolic function has been evaluated in patients with RA, mitral valve movement has been measured. In these studies, E-F slope has been reported to be decreased $[22,23]$ but in some other studies $[20,21]$ E-F slope was normal. However, E-F slope is unspecific for the evaluation of diastolic filling, as structural changes in mitral valve can also interfere with mitral valve movement. On the other hand, Mustonen et al. [9] pointed out that RA patients had a longer isovolumic relaxation time and a lower peak filling rate in comparison with control subjects. But, no echo-Doppler data were available.

For all these reasons, we studied left ventricular filling by Doppler echocardiography, which provides a reliable non-invasive method for assessing left ventricular diastolic function [24,25]. Many factors can affect mitral flow velocity measurements [26-28]. For this reason, we applied a strict selection process for both patients and matched controls. In particular, we selected subjects without any valvular regurgitation and/or stenosis, and any other associated disease that can affect mitral flow measurements.

Our results indicate that patients with RA have a different mitral flow velocity pattern compared with controls. In the patients we found an increased mitral flow velocity at atrial contraction and an increased $\mathrm{A} / \mathrm{E}$ ratio. As subjects were selected to clinically exclude loading alterations and other factors that can affect diastolic filling, there is no reason to think that the two groups were not homogeneous and comparable. Therefore, our echo-Doppler findings may be due to impaired left ventricular diastolic function. Moreover, this pattern appears to occur when there is impaired left ventricular relaxation [29].

Thus, our results confirm diastolic abnormalities in RA patients and point out that these abnormalities also concern left ventricular filling detected by echo-Doppler examination of transmitral blood flow.

What is the clinical meaning of such abnormalities? Diastolic dysfunction has been recognized as a primary cause of congestive heart failure [10]. In RA patients an increased prevalence of congestive heart failure is well documented. Such an increased morbidity does not seem related to hypertension or ischaemic heart disease; it could be due to a more extensive involvement of the heart with consequent changes in left ventricle structure that might manifest themselves in abnormalities of left ventricular diastolic function, afterwards leading to left ventricular systolic dysfunction. As no specific tissue typing studies were performed in our patients, we can only guess that these diastolic abnormalities could be caused by left ventricular structural alterations (i.e. an increase or modification of the interstitial connective tissue within the myocardium). This hypothesis is at least partially supported by our data. In fact, using appropriate statistical methodology, we found that only in RA patients was the $\mathrm{A} / \mathrm{E}$ ratio significantly and independently correlated to LVM, even when normalized to height and BSA, and not to age or left ventricular wall 
thickness. All the RA patients were normotensive and without clinically evident cardiac or extracardiac diseases. Moreover, they were perfectly comparable with the control subjects. Therefore, it can be reasonably excluded that a complaint different from rheumatoid arthritis could explain the highest mean LVMI and the abnormalities in left ventricular filling that we found. In addition the $\mathrm{A} / \mathrm{E}$ ratio was independently correlated with LVM only in rheumatoid patients. Consequently, a possible explanation could be that structural myocardial changes occurred in our patients.

Diastolic abnormalities have also been observed in other inflammatory joint diseases [10]. For this reason, we think these alterations may represent a common non-specific consequence of the chronic inflammatory process.

In conclusion, our data may suggest the possibility that structural myocardial changes could be responsible for the impaired left ventricular filling we found in RA patients. Further investigations into the clinical and pathological nature of these lesions will be important and may suggest approaches to prophylactic treatment.

\section{References}

1 Prior P, Symmons DPM, Scott DL, Brown R, Hawkins CF. Cause of death in rheumatoid arthritis. Br J Rheumatol 1984; 23:92-9.

2 Vanderbroucke JP, Hazevoet HM, Cats A. Survival and cause of death in rheumatoid arthritis: a 25 year prospective follow-up. J Rheumatol 1984;11:158-61.

3 Mutru O, Laasko M, Isomäki H, Koota K. Ten year mortality and causes of death in patients with rheumatoid arthritis. Br Med J 1984;290:1811-13.

4 Laasko M, Mutru O, Isomäki H, Koota K. Mortality from amyloidosis and renal diseases in patients with rheumatoid arthritis. Ann Rheum Dis 1986;45:663-7.

5 Mutru O, Laasko M, Isomäki H, Koota K. Cardiovascular mortality in patients with rheumatoid arthritis. Cardiology 1989;76:71-7.

6 Corrao S, Sallì L, Arnone S et al. Cardiac involvement in rheumatoid arthritis: evidence of silent heart disease. Eur Heart J, 1995; 16:253-6.

7 Ind PW, Lewis P. Systemic hypertension in rheumatic disease. In: Ansell BM, Simkin PA, ed. The heart and rheumatic diseases. Butterworths International Medical Reviews. Rheumatology. London, Butterworths, 1984:186-212.

8 Cathcart ES, Spodick DH. Rheumatoid heart disease. A study of the incidence and nature of cardiac lesions in rheumatoid arthritis. $\mathrm{N}$ Engl J Med 1962;266:959-64.

9 Mustonen J, Laasko M, Hirvonen T et al. Abnormalities in left ventricular diastolic function in male patients with rheumatoid arthritis without clinically evident cardiovascular disease. Eur J Clin Invest 1993;23:246-53.

10 Rowe IF, Gibson DG, Keat ACS, Breweton DA. Echocardiographic diastolic abnormalities of the left ventricle in inflammatory joint disease. Ann Rheum Dis 1991;50:227-30.

11 Arnett FC, Edworthy SM, Bloch DA et al. The American
Rheumatism Association 1987 revised criteria for the classification of Rheumatoid Arthritis. Arthritis Rheum 1988;31:315-24.

12 Sahn DJ, DeMaria A, Kisslo J, Weyman A. Recommendations regarding quantitation in m-mode echocardiography: results of a survey of echocardiographic measurements. Circulation 1978; 58:1072-83.

13 Devereux RB, Reichek N. Echocardiographic determination of left ventricular mass in man. Anatomic validation of the method. Circulation 1977;55:613-18.

14 Devereux RB, Alonso DR, Lutas EM et al. Echocardiographic assessment of left ventricular hypertrophy: comparison to necropsy findings. Am J Cardiol 1986;57:450-8.

15 Wyatt HL, Meerbaum S, Heng MK, Gueret P, Corday E. Cross sectional echocardiography III. Analysis of mathematic models for quantifying volume of symmetric and asymmetric left ventricle. Am Heart J 1980;100:821-8.

16 Corrao S, Parrinello G, Arnone S, Indovina A, Scaglione R, Licata $\mathrm{G}$. Influence of obesity on the echocardiographic evaluation of left ventricular ejection fraction by area-length method: comparison with radionuclide angiography. J Cardiovasc Diagn Proc 1993;11: 127-34.

17 Missri J. Clinical Doppler Echocardiography. Spectral and Color Flow Imaging. McGraw-Hill Information Services 1990:28-42.

18 Corrao S, Scaglione R, Arnone S, Licata G. Left ventricular diastolic filling alterations in subject with mitral valve prolapse: a Doppler echocardiographic study. Eur Heart J 1993;14:369-72.

19 Fujii J, Yazaki Y, Sawada H, Aizawa T, Watanabe H, Kato K. Non invasive assessment of left and right ventricular filling in myocardial infarction with a two-dimensional Doppler echocardiographic method. J Am Coll Cardiol 1985;5:1155-60.

20 MacDonald WJ, Crawford MH, Klippel JH, Zvaifler NJ, O'Rourke RA. Echocardiographic assessment of cardiac structure and function in patients with rheumatoid arthritis. Am J Med 1977;65:921-8.

21 Mody GM, Stevens JE, Meyers OL. The heart in rheumatoid arthritis - a clinical and echocardiographic study. Q J Med 1987; 65:921-28.

22 Prakash R, Atassi A, Poske R, Rosen KM. Prevalence of pericardial effusion and mitral valve involvement in patients with rheumatoid arthritis without cardiac symptoms. An echocardiographic evaluation. N Engl J Med 1973;289:597-600.

23 Bacon PA, Gibson DG. Cardiac involvement in rheumatoid arthritis. An echocardiographic study. Ann Rheum Dis 1974; 33:20-4.

24 Spirito P, Maron BJ, Bellotti P, Chiarella F, Vecchio C. Non invasive assessment of left ventricular diastolic function: comparative analysis of Pulsed Doppler Ultrasound and digitized m-mode echocardiography. Am J Cardiol 1986;58:837-43.

25 Spirito P, Maron BJ, Bonow RO. Noninvasive assessment of left ventricular diastolic function: comparative analysis of Doppler echocardiographic and radionuclide angiographic techniques. J Am Coll Cardiol 1986;7:518-26.

26 Gardin J, Dabestani A, Takenaka K et al. Effects of imaging view and sample volume location on evaluation of mitral flow velocity by pulsed Doppler echocardiography. Am J Cardiol 1986;57:1335-9.

27 Riggs TW, Transue D. Doppler echocardiographic evaluation of left ventricular diastolic function in adolescents with diabetes mellitus. Am J Cardiol 1990;65:889-902.

28 Ishida Y, Meisner J, Tsujioka K et al. Left ventricular filling dynamics: influence of left ventricular relaxation and left atrial pressure. Circulation 1986;74:186-96.

29 Appleton C, Atle L, Popp RL. Relation of transmitral flow velocity patterns to left ventricular diastolic function: new insights from a combined hemodynamic and Doppler echocardiographic study. J Am Coll Cardiol 1988;12:426-35. 